\title{
Optimization of Adiabatic Inverter Transformers
}

\author{
James P. O'Loughlin, Steve E. Calico, Diana L. Loree \\ U.S. Air Force Phillips Laboratory \\ PL/WS, HERTF \\ Kirtland AFB, NM 87117-5776
}

\section{Introduction}

A major weight component in switching type power inverters is the power transformer. The design method presented in this paper provides for a reduction in the transformer weight, for intermittent duty units, which is at least an order of magnitude lighter than conventional transformer designs. In the special applications of significance to the Air Force, [i.e., very high power ( 10 's to 1000 's of $\mathrm{kW}$ ), very weight sensitive, limited time missions ( 5 to 120 Seconds)], the weight of the power conditioning inverter transformer all but disappears. The transformer weight is minimized by optimizing the geometric configuration and in addition by designing the transformer for adiabatic operation and a maximum temperature rise over the mission time consistent with reliable operation. The burst times considered are up to about 75 seconds. The reliable maximum operating temperature is based on using high temperature materials and assuming that the number of operational life cycles for the application is on the order of a few hundred. This suggests a maximum temperature rise of about 200 degrees (C). Thermal end of life is determined by insulation failure. The failure for class $\mathrm{C}$ (or $\mathrm{H}$ ) materials is based on 2500 hours of continuos operation at 180 degrees $\mathrm{C}$. The estimated life at 250 degrees is about 20 hours of continuos operation. Based on these operating parameters and the known transformer core material characteristics it is shown that truly remarkable transformer specific power ratings on the order of one(1) MW/kg (at 5 to 10 second bursts) are feasible at nominal voltage ratings up to $5 \mathrm{kV}$. Specific powers are shown in Fig.1 and have been verified from a point design.

\section{Core Material}

Several core materials were considered including: ferrite, nickel alloys, metallic-glass, Vanadium Alloy (Supermendur) and grain-oriented silicon steel. The core loss of metal tape or laminations can be estimated by the Steinmetz equation ${ }^{[1]}$ of the form:

$$
\text { (1) } \mathrm{W}=\mathrm{a}_{1} \mathrm{f} \mathrm{B}_{\mathrm{T}}{ }^{1.6}+\mathrm{a}_{2} \mathrm{f}^{2} \mathrm{~B}_{\mathrm{T}}^{2}
$$

Where:

$$
\begin{aligned}
& \mathrm{W}=\text { core loss in Watts } / \mathrm{kg} \\
& \mathrm{f}=\text { frequency in Hertz } \\
& \mathrm{B}_{\mathrm{T}}=\text { flux density in Tesla } \\
& \mathrm{a}_{1}, \mathrm{a}_{2}=\text { constants depending on material }
\end{aligned}
$$

The constants $\mathrm{a}_{1}, \mathrm{a}_{2}$ are given in Table I for 0.001 , 0.002 and 0.004 (inch) grain oriented silicon steel core material ${ }^{[2]}$. Other material characteristics can be obtained from manufactures data.

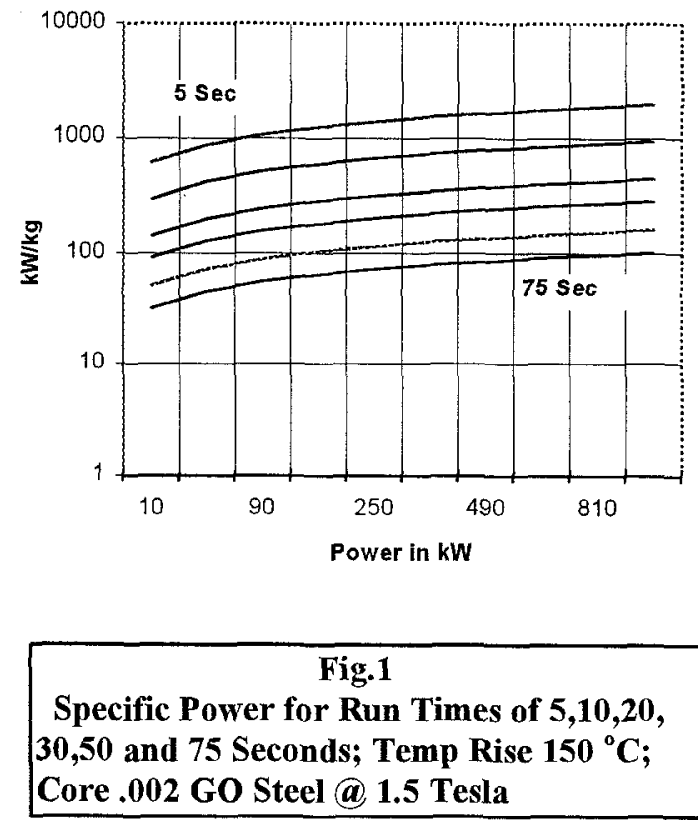

Table I

$\begin{array}{lcc}\text { GO Steel Gauge } & \mathrm{a}_{1} & \mathrm{a}_{2} \\ .001 \text { (inches) } & 1.328 \mathrm{e}-2 & 7.617 \mathrm{e}-7 \\ .002 \text { (inches) } & 2.243 \mathrm{e}-2 & 2.444 \mathrm{e}-6 \\ .004 \text { (inches) } & 2.283 \mathrm{e}-2 & 1.257 \mathrm{e}-5\end{array}$


Silicon steel is the most practical choice for economic and fabrication reasons. In special cases other materials may be advantageous. Ferrites are commonly used in inverter transformers however they are not suitable for high temperature rise adiabatic designs considered here because of low Curie temperatures $(\sim 130$ $150{ }^{\circ} \mathrm{C}$ ) and the fact that the saturation flux density is relatively low and falls considerably with even a modest rise in temperature.

The heat capacity of the core steel is $448 \mathrm{~J} / \mathrm{kg} /{ }^{\circ} \mathrm{C}$ or a core loss of $448 \mathrm{Watts} / \mathrm{kg} /{ }^{\circ} \mathrm{C} / \mathrm{sec}$. If the temperature rate of rise in ${ }^{\circ} \mathrm{C} / \mathrm{sec}$ is $\mathrm{T}^{\circ}$ then the core loss, W, can be replaced in equation (1), yielding:

(2) $448 \mathrm{~T}^{\circ}=\mathrm{a}_{1} \mathrm{fB}_{\mathrm{T}}^{1.6}+\mathrm{a}_{2} \mathrm{f}^{2} \mathrm{~B}_{\mathrm{T}}{ }^{2}$ Watts $/ \mathrm{kg}$

This equation can be solved for the frequency $f$ $\left(\mathrm{B}_{\mathrm{T}}, \mathrm{T}^{\mathrm{o}}\right)$ as:

$$
\text { (3) } \begin{aligned}
\mathrm{f}=-\mathrm{B}_{\mathrm{T}}^{-0.4} \mathrm{a}_{\mathrm{l}} /\left(2 \mathrm{a}_{2}\right) \\
+\left[\left(\mathrm{a}_{1} / \mathrm{a}_{2}\right)^{2} \mathrm{~B}_{\mathrm{T}}^{-0.8} / 4-448 \mathrm{~T}^{\circ} \mathrm{B}_{\mathrm{T}}^{-2}\right]^{1 / 2}
\end{aligned}
$$

Equations (3) tells us the frequency which will cause the core material to rise at a rate of $T^{\circ}$ when the flux density is $B_{T}$.

The function of the core is to support an applied voltage on the primary and provide an induced voltage in the secondary. A figure of merit of this function can be expressed in terms of volts per turn per unit of core area as:

(4) $\quad \underline{V} / \mathrm{T}=4.469 \mathrm{~B}_{\mathrm{T}} \mathrm{f} \quad$ volts per turn per square meter

The maximum utilization of the material occurs when the maximum V/T is achieved. It can be shown that the maximum utilization occurs when the maximum flux density is used. For silicon steel the practical limit is taken as 1.5 Tesla; however, operation to 1.75 Tesla is feasible. With $\mathrm{B}_{\mathrm{T}}$ set to 1.5 Tesla in equation (3) the optimum frequency is plotted in Fig. 2 as a function of the rate of temperature rise $\mathrm{T}^{\circ}$ for $.001, .002$ and .004 mil silicon steel core material. The optimum utilization of the core material is independent of the core geometry and the utilization of the winding material and geometry. However, the optimized over-all transformer is a combination of all of these considerations.

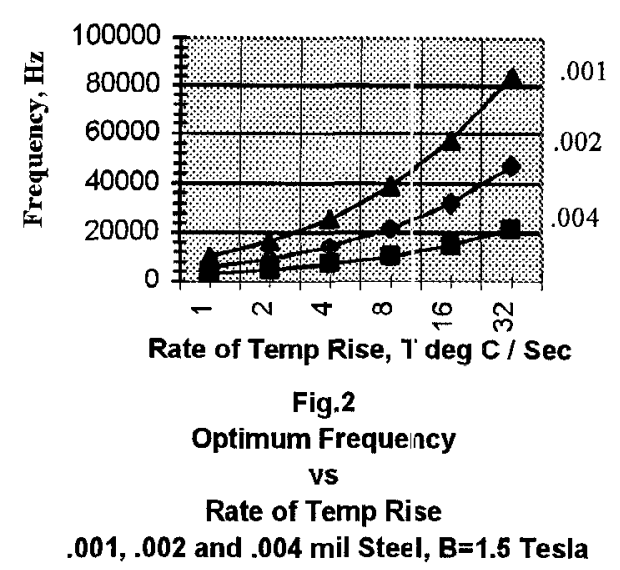

\section{Winding Material}

The most practical conductor material for the transformer coil is copper with a high temperature insulation. Materials such as Teflon, glass, certain polyesters, and others are suitable for limited life operation up to $250{ }^{\circ} \mathrm{C}$.

Imposing adiabatic conditions, the current density is determined by the operating time and the temperature rise. For a temperature rise of $\mathrm{T}^{\circ}{ }^{\circ} \mathrm{C}$. The current density as a function of time $t$ is given by:

(5) $\mathrm{J}=\left[\left(\sigma * \delta * \mathrm{~T}^{\prime}\right) /\left(\mathrm{t} * \rho *\left(\mathrm{I}+\alpha^{*} \mathrm{~T}^{\prime}\right)\right)\right]^{\wedge} 0.5$

where: $J=$ current density in $\mathrm{A} / \mathrm{cm}^{2}$

$\sigma=$ Heat Capacity, $\mathrm{J} / \mathrm{g}=0.385(\mathrm{Cu})$

$\delta=$ specific gravity, $8.96 \mathrm{~g} / \mathrm{cc}(\mathrm{Cu})$

$\mathrm{t}=$ time of adiabatic operation

$\rho=$ resistivity ohm-cm, $1 . " 24 \mathrm{e}-6(\mathrm{Cu})$

$\alpha=$ Temp Coef of Resistance, $.00393(\mathrm{Cu})$

$\mathrm{T}^{\prime}=$ Temperature Rise over the period $\mathrm{t}$

(5a) $\mathrm{J}=1414\left[\mathrm{~T}^{\prime} /\left(\mathrm{t} *\left(1+.00393 \mathrm{~T}^{\prime}\right)\right]^{\wedge} 0.5\right.$ $\mathrm{A} / \mathrm{cm}^{2}$ for Copper

The temperature considerations for the winding are different from those of the core because of the dependence of the resistivily of copper on temperature. For the core it was possible to take a constant rate of temperature rise. Not so for the winding because the rate of rise is itself a function of the temperature therefore the total temperature rise over the period $t$ is used when dealing with the winding. One should also be aware that at inverter frequencies skin effect san be a factor. 
The skin depth for copper is given by ${ }^{[3]}$ :

(6) $\delta=6.61 / \mathrm{f}^{1 / 2} \quad$ [Skin depth in $\mathrm{cm}, \mathrm{f}$ in $\mathrm{Hz}$ ]

The increase in effective resistance is approximately given by ${ }^{[3]}$.

$$
\mathrm{R}_{\mathrm{ac}} / \mathrm{R}_{\mathrm{dc}}=0.0378 \mathrm{Df}^{1 / 2}+.026 \text {; }
$$

[Valid for values of $\mathrm{D} \mathrm{f}^{1 / 2}>40$; $\mathrm{D}$ is the wire diameter in $\mathrm{cm}$.]

Skin effect problems can be solved by using small diameter parallel wires such as Litz wire.

\section{Transformer Configuration Optimization}

The optimum geometric configuration of a transformer can be determined using the ratio's of the core dimensions as shown in Fig.3 and the core and coil densities.

There is also a dependence on the operating voltage which can be generalized in terms of space factor or density which accounts for the additional insulation at higher voltages. The optimization procedure defines the transformer power at constant weight in terms of the optimization parameters. Both one-winding-two-core and twowinding-one-core configurations are analyzed, see Fig.3. The power at fixed weight expressions are then optimized by a computerized sweep of the configuration parameters thus determining the optimum geometric configuration. The equations for power at fixed weight for the two configurations are:

$\mathrm{P}_{2 \mathrm{wlc}}=\frac{\left[\mathrm{S}_{\mathrm{c}}{ }^{2 / 3} * \mathrm{~J}^{*} \mathrm{~V}_{\mathrm{T}} * \mathrm{~W}_{\mathrm{T}}^{4 / 3}\right]^{*} \mathrm{a}^{*} \mathrm{~b}^{*} \mathrm{~g}^{2 *} \mathrm{~d}}{2^{7 / 3} \mathrm{~d}_{\mathrm{w}}{ }^{*} \mathrm{~d}_{\mathrm{c}}^{1 / 3} *\left[\mathrm{~b}^{*}\left(\mathrm{~g}+\mathrm{a}^{*} \mathrm{~g}+2\right)+\mathrm{a}^{*} \mathrm{~g}^{2 *}(1+\mathrm{b}+\mathrm{g}) * \mathrm{~d}\right]^{4 / 3}}$

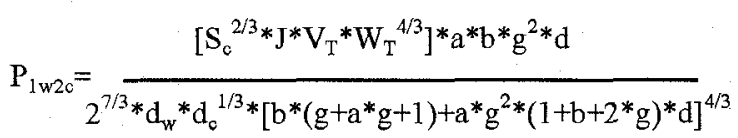

where: $\quad d=S_{w} d_{w} / S_{c} d_{c}$

$\mathrm{S}_{\mathrm{w} / 0}=$ Space Factor of Winding/Core

$\mathrm{d}_{\mathrm{w} / \mathrm{o}}=$ Density of Winding/Core

The optimization results are shown in Fig. $3 \mathrm{~A}$ and Fig. 3B.

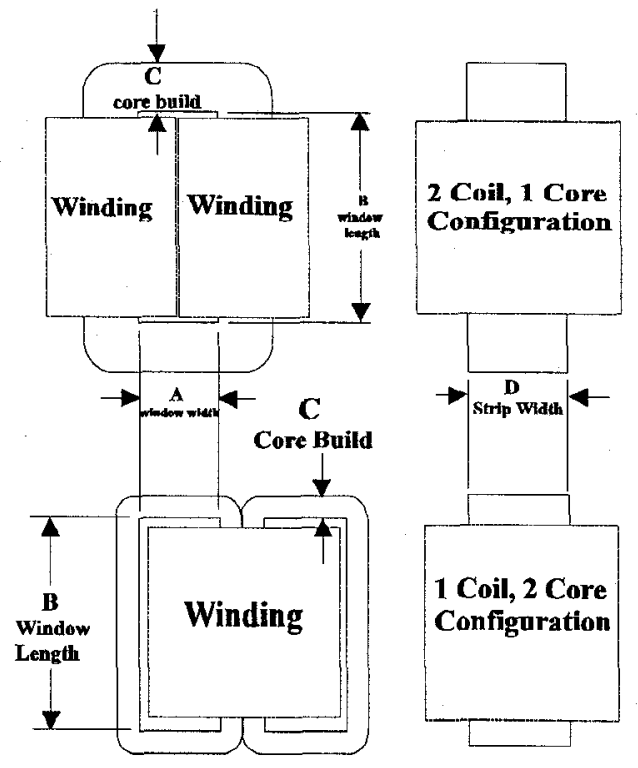

Fig.3

Transformer Configurations Transformer Configuration Parameters $\mathbf{a}=\mathbf{B} / \mathbf{A} \quad \mathbf{b}=\mathbf{D} / \mathbf{C} \quad \mathbf{g}=\mathbf{A} / \mathbf{C}$ $d=S_{w} d_{w} / S_{c} d_{c}$
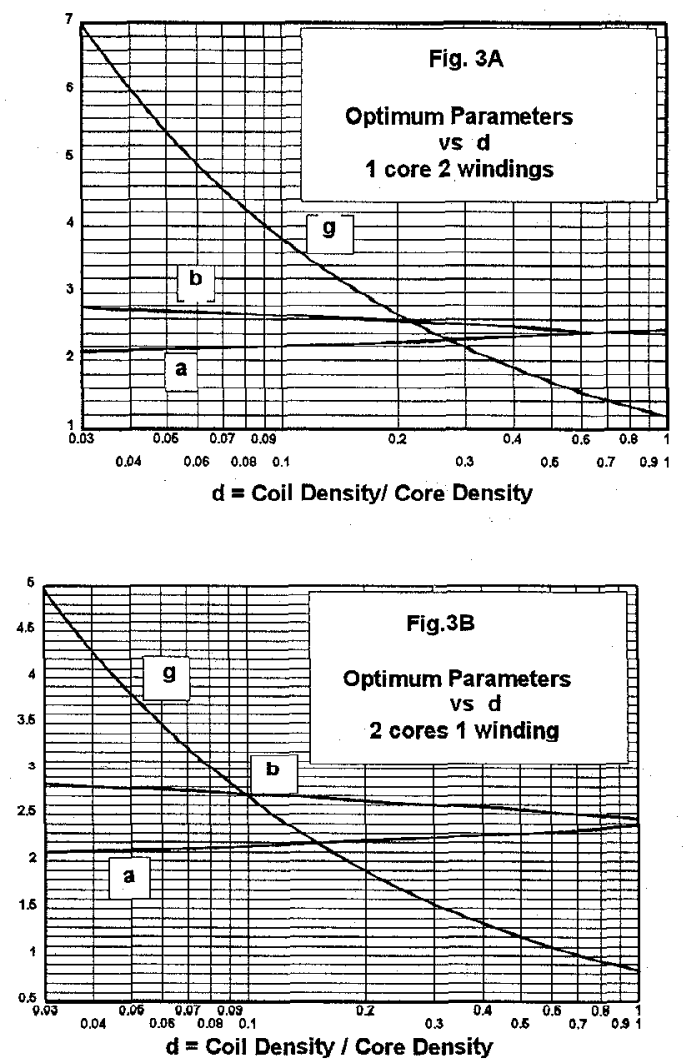
Point Design Example The following point design is given to illustrate the subject design method. The point design is to have a temperature rise of 150 degrees $\mathrm{C}$ over an operating period of 30 seconds or $5{ }^{\circ} \mathrm{C}$ per second. The core material is .002 mil grain oriented steel. The primary voltage is 1350 volts and the secondary is $5 \mathrm{kVrms}$. The core characteristics are shown in Fig.4.

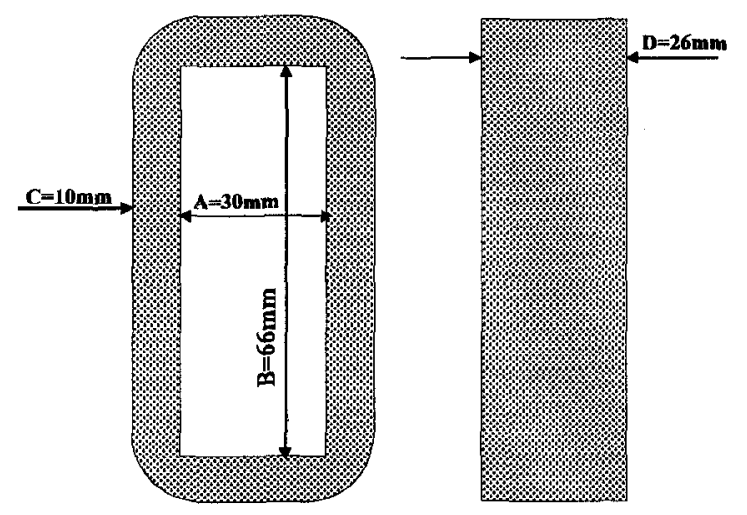

Fig.4 Point Design Core

Material .002 GO Silicon Steel

Area $2.6 \mathrm{sq} \mathrm{cm}$, Weight $0.396 \mathrm{~kg}$

Geometric Parameters, $\mathrm{a}=2.2, \mathrm{~b}=\mathbf{2 . 6}, \mathrm{g}=3.0$

See Fig. 3A

Using equation (3) the optimum frequency is determined as $16,386 \mathrm{~Hz}$. The volts per turn are determined by equation (4) as 25.178. Thus the primary and secondary turns are 49 and 208 allowing $5 \%$ regulation. The current density is determined from equation (5) as $2508 \mathrm{~A} / \mathrm{cm}^{2}$. The configuration used is one core/two coils as in Fig.3. By cut-and-try it is determined that 4 - \#20 wires in parallel wound in 4 layers plus 4 layers of \#20 in series for the secondary will fit the core. See Table II for the coil build calculation.

\section{Table II, Coil Build Calculation}

\begin{tabular}{ll} 
Coil Form & $1.00 \mathrm{~mm}$ \\
4 layers \#20 (Py) & $3.76 \mathrm{~mm}$ \\
layer ins & $0.38 \mathrm{~mm}$ \\
shield \& insulation & $1.50 \mathrm{~mm}$ \\
4 layers \#20 (Sy) & $3.76 \mathrm{~mm}$ \\
layer ins & $0.38 \mathrm{~mm}$ \\
Sy wrap & $1.00 \mathrm{~mm}$ \\
\hline \multicolumn{1}{c}{ Total for each coil } & $12.54 \mathrm{~mm}$
\end{tabular}

Both coils together occupy $85 \%$ of the $30 \mathrm{~mm}$ window and therefore meet the fabrication needs. From equation (6) the skin depth is $0.516 \mathrm{~mm}$ and the diameter of \#20 wire is $0.406 \mathrm{~mm}$ therefore the skin effect is under control. At the current density of $2508 \mathrm{~A} / \mathrm{cm}^{2} \# 20$ wire will carry $13 \mathrm{~A}$. Therefore the output of the two \#20 secondary wires is $26 \mathrm{~A}$ or a power of $130 \mathrm{~kW}$ for 30 seconds. The winding and core weights and losses are tabulated in Table III.

\begin{tabular}{lcc} 
& \multicolumn{2}{c}{ Table III, Weights and Losses } \\
Item & weight & Loss \\
Core & $0.396 \mathrm{~kg}$ & $1292 \mathrm{~W}$ \\
Py winding & $0.075 \mathrm{~kg}$ & $81 \mathrm{~W}$ \\
Sy winding & $0.123 \mathrm{~kg}$ & $338 \mathrm{~W}$ \\
Misc & $0.156 \mathrm{~kg}$ & $0.00 \mathrm{~W}$ \\
\hline Total & $0.75 \mathrm{~kg}$ & $1292 \mathrm{~W}$
\end{tabular}

The efficiency is $130 \mathrm{~kW} / 131.292 \mathrm{~kW}=99 \%$. The core density is $6.817 \mathrm{~g} / \mathrm{cc}$ and the coil density is $0.876 \mathrm{~g} / \mathrm{cc}$, therefore the ratio (See Fig. 3) which is the parameter $d$ is 0.128 . The specific power is $173 \mathrm{~kW} / \mathrm{kg}$.

\section{Conclusion}

When the choice of operating fiequency is permitted in the design of an adiabatic transformer, such as an inverter transformer, another degree of freedom is available for the design optimization. Further improvements are also possible by optimization of the configuration geometry. When both of these factors are used to advantage, specific weights on the order of $100 \mathrm{~kW} / \mathrm{kg}$ to over $1000 \mathrm{~kW} / \mathrm{kg}$ are possible with respective adiabatic run duration's of 75 seconds to 5 seconds, as shown in Fig.1.

\section{References}

[1] Steinmetz,C.P.,"Note on the: Law of Hysteresis", The Elect. Eng.,vol. X, pp. 677-678, Dec. 17, 1890.

[2] Electrical Materials Handbcok, Allegheny Ludlulm Steel Corp, 1961.

[3] Reference Data for Radio Engineers, 4th Edition, ITT Corp,pp128-131, 1957. 